Fixed Point Theory, 22(2021), No. 2, 671-684

DOI: $10.24193 /$ fpt-ro.2021.2.44

http://www.math.ubbcluj.ro/ nodeacj/sfptcj.html

\title{
SOLVABILITY OF NONLINEAR FUNCTIONAL DIFFERENTIAL EQUATIONS OF FRACTIONAL ORDER IN REFLEXIVE BANACH SPACE
}

\author{
H.H.G. HASHEM* ${ }^{*}$, A.M.A. EL-SAYED**, RAVI P. AGARWAL*** AND BASHIR AHMAD**** \\ *Department of Mathematics, College of Science, Qassim University, \\ P.O. Box 6644 Buraidah 51452, Saudi Arabia \\ E-mail: 3922@qu.edu.sa \\ **Faculty of Science, Alexandria University, Alexandria, Egypt \\ E-mail: amasayed@alexu.edu.eg \\ *** Department of Mathematics, Texas A and M University, Kingsville, USA \\ E-mail: Agarwal@tamuk.edu \\ **** Faculty of Science, King Abdulaziz University, \\ P.O. Box 80203, Jeddah 21589, Saudi Arabia \\ E-mail: bashirahmad-qau@yahoo.com
} problems of fractional order and their corresponding functional integral equation of fractional order. These initial value problems includes many initial value problems that arise in nonlinear analysis and its applications.

Key Words and Phrases: Fractional Pettis integral, weakly relatively compact, functional differential equation, O'Regan fixed point theorem.

2020 Mathematics Subject Classification: 34A12, 47G10, 28B05, 47H10.

\section{REFERENCES}

[1] R.P. Agarwal, V. Lupulescu, D. O'Regan, G. Rahman, Nonlinear fractional differential equations in nonreflexive Banach spaces and fractional calculus, Advances in Difference Equations, (2015), 2015:112.

[2] J.M. Ball, Weak continuity properties of mapping and semi-groups, Proc. Royal Soc.Edinbourgh Sect., A72(1973-1974), 275-280.

[3] S.N. Chow, J. Shur, An existence theorem for ordinary differential equations in Banach spaces, Bull. Amer. Math. Soc., 77(1971), 1018-1020.

[4] M. Cichon, On bounded weak solutions of a nonlinear differential equations in Banach spaces, Funct. Approx., 21(1992), 27-36.

[5] M. Cichoń, Weak solutions of differential equations in Banach spaces, Discuss. Math. Differ. Inc., 15(1995), 5-14.

[6] M. Cichoń, I. Kubiaczyk, Kneser's theorem for strong, weak and pseudo-solutions of ordinary differential equations in Banach spaces, Ann. Pol. Math., 52(1995), 13-21.

[7] K. Deimling, Ordinary Differential Equations in Banach Spaces, Lecture Notes in Mathematics, Vol. 596, Springer, Berlin 1977. 
[8] J. Diestel, J.J. Uhl Jr., Vector Measures, Math. Surveys 15, Amer. Math. Soc., Providence, RI, 1977.

[9] A.M.A. El-Sayed, E.O. Bin-Taher, Nonlocal and integral conditions problems for a multi-term fractional-order differential equation, Miskolc Mathematical Notes, 15(2014), no. 2, 439-446.

[10] A.M.A. El-Sayed, N.F.M. El-Haddad, Weak solutions of a functional integral equation in reflexive Banach space, Nonlinear Analysis and Differential Equations, 4(2016), no. 7, 305-313.

[11] A.M.A. El-Sayed, W.G. El-Sayed, A.A.H. Abd El-Mowla, A coupled system of functional differential equations in reflexive Banach spaces, International Journal of Pure and Applied Mathematics, 113(2017), no. 1, 35-42.

[12] A.M.A. El-Sayed, H.H.G. Hashem, Weak maximal and minimal solutions for Hammerstein and Urysohn integral equations in reflexive Banach spaces, Differential Equation and Control Processes, 4(2008), 50-62.

[13] A.M.A. El-Sayed, H.H.G. Hashem, Coupled systems of Hammerstein and Urysohn integral equations in reflexive Banach spaces, Differential Equations and Control Processes, 1(2012), $1-12$.

[14] A.M.A. El-Sayed, H.H.G. Hashem, Coupled systems of integral equations in reflexive Banach spaces, Acta Mathematica Scientia, 32B(5)(2012), 1-8.

[15] A.M.A. El-Sayed, H.H.G. Hashem, A coupled system of fractional order integral equations in reflexive Banach spaces, Commentationes Mathematicae, 52(2012), 21-28.

[16] R.F. Geitz, Pettis integration, Proc Amer. Math. Soc., 82(1981), 81-86.

[17] H.H.G. Hashem, Weak solutions of differential equations in Banach space, Journal of Fractional Calculus and its Applications, 3(2012), 1-9.

[18] H.H.G. Hashem, Y. Khouni, A survey on existence results of some differential and integral equations in abstract spaces, Journal of Fractional Calculus and its Applications, 8(2017), 126141.

[19] I. Kubiaczyk, On fixed point theorem for weakly sequentially continuous mappings, Discuss. Math. Differ. Incl., 15(1995), 15-20.

[20] A.R. Mitchell, Ch. Smith, An existence theorem for weak solutions of differential equations in Banach spaces, in: Nonlinear Equations in Abstract Spaces, V. Lakshmikantham (ed.), 1978, 387-403.

[21] D. O'Regan, Fixed point theory for weakly sequentially continuous mapping, Math. Comput. Modelling, 27(1998), 1-14.

[22] D. O'Regan, Weak solutions of ordinary differential equations in Banach spaces, Appl. Math. Lett., 12(1999), 101-105.

[23] B.J. Pettis, On integration in vector spaces, Trans. Amer. Math. Soc., 44(1938), 277-304.

[24] H.A.H. Salem, M. Cichon, On solutions of fractional order boundary value problems with integral boundary conditions in Banach spaces, Journal of Function Spaces and Applications, 2013(2013), Article ID 428094, 13 pages.

[25] H.A.H. Salem, A.M.A. El-Sayed, Weak solution for fractional order integral equations in reflexive Banach spaces, Math. Slovaca, 55(2005), 169-181.

[26] A. Szep, Existence theorem for weak solutions of ordinary differential equations in reflexive Banach spaces, Studia Sci. Math. Hungar., 6(1971), 197-203.

[27] S. Szulfa, On the existence of solutions of differential equations in Banach spaces, Bull. Acad. Polan. Sci. Ser. Sci. Math., 30(1982), 507-514.

Received: October 3, 2019; Accepted: January 7, 2020. 
FRACTIONAL FUNCTIONAL DIFFERENTIAL EQUATIONS 